\title{
Cardiac hydatidosis : A rare infection of the heart with hydatid cyst of Echinococcus
} granulosus can produced anaemia

\author{
Amal Kh. Khalaf
}

Department of microbiology . College of medicine . University of Thi-qar

\begin{abstract}
$\underline{\text { Abstract }}$
Rarely, heart was infected with hydatid cyst of E. granulosus, where the current study were recorded only one infection of heart with hydatid cyst among 225 male of mice experimentally infected with hydatid cyst leading to produced anaemia. Histological examination of hydatid cyst components was explained presence of three layers include fibrous layer, laminated layer, and germinal layer or endocyst. So there is a granulomatous fibrous tissue in the pericardium.
\end{abstract}

Key words: hydatid cyst, Cardiac hydatidosis, E. granulosus.

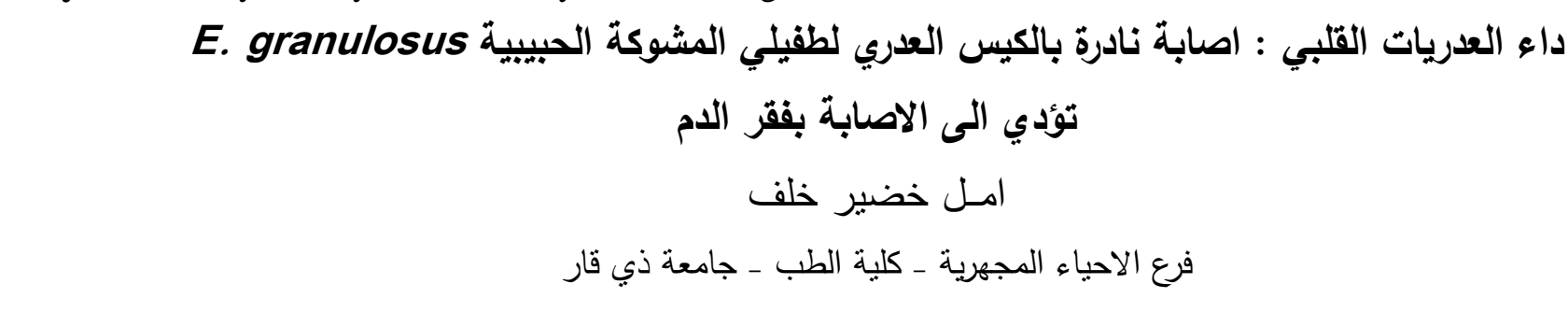

E. granulosus داء العدريات القلبي : اصابة نادرة بالكيس العدري لطفيلي المشوكة الحبيبية

امـل خضير خلف

فرع الاحياء المجهرية ـ كلية الطب - جامعة ذي قار

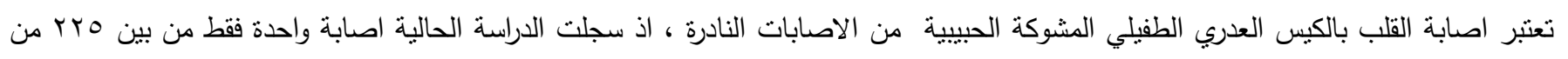

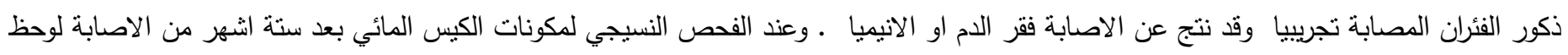

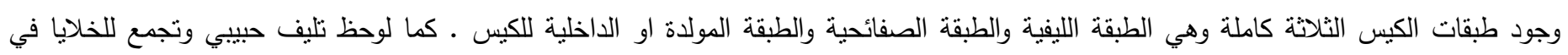

\section{Introduction}

There are two types of Echinococcus infections. E. granulosis is the more common type, whereas $E$. multilocularis is less common but more invasive, mimicking a malignancy. Hydatid disease (HD) continues to be a significant health problem in underdeveloped areas where animal husbandry is common but no veterinary control exists (eg, parts of South America, the Mediterranean region, the Middle East, Africa, and Australia). In Europe, $\mathrm{HD}$ is uncommon and is seen only in immigrants or persons with a history of travel to endemic areas (Pedrosa et al., 2000). When produced, after a highly variable incubation period, symptoms are diverse with varying degrees of severity that are never suggestive of Echinococcosis . Symptoms may become apparent if the cyst ruptures or exerts a mass effect (Kilani et al., 2001). The symptoms are determined by organ of localization, size of the cyst and their condition. The organ most commonly involved is the liver (50-70\%), followed by lungs (20-30\%) and other organs (like the spleen, kidney, heart, bones, central nervous system etc.) in less than $10 \%$ of the cases. Infection is mostly acquired during the childhood in patients in which the disease is diagnosed between 10 to 50 years of age (Tuzun and Hekimoglu, 2001).

\section{Materials and methods}

-Parasite Materials and experimental mice infection:

Fresh hydatid cysts were obtained from livers and lungs of naturally-infected sheep, which had been slaughtered at local abattoirs in Nasseriyah. They were wrapped carefully in clean plastic bags, placed in an ice box, and transported to the Department of Microbiology , College of medicine, Thi-qar University, where protoscolices were isolated according to Smyth (1964) method . Protoscolices indicates the fertility of hydatid cyst and its were counted according to method cited by Al- Humairy (2010). The viable protoscolices were counted in $1 \mathrm{ml}$ based on the formula : 
Viability in $1 \mathrm{ml}=$ number of protoscolices in $(10 \mu \mathrm{l})$ $\times 100$

225 male of Mus musculus mice BalblC strain were injected with $0.2 \mathrm{ml} \mathrm{480/} \mathrm{ml}(2400 / 5 \mathrm{ml}$ rate of viability) of protoscolices intraperitoneally and consider as positive group and left for six months.
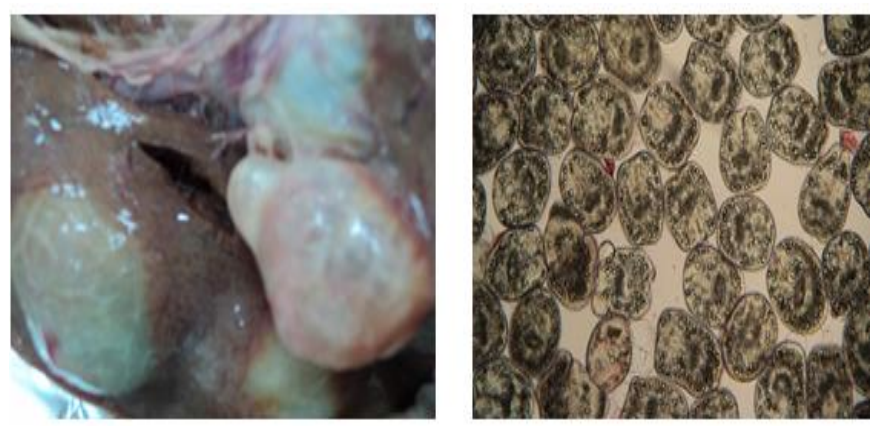

Hydatid cyst with isolated protoscolices

\section{- The Study of the effect of infection on blood Parameters}

The hematological examination were carried out to determine the overall health of the animals after infection to determine the effects of the infection on animals blood parameters. The tests were carried out as described by previous researchers (Schalm et al., 1975 and Jain, 1986) . Blood samples were obtained from the heart of each animal after dissecting using $1 \mathrm{ml}$ volume syringe. The samples of blood was placed into a vial containing EDTA for the determination of hemoglobin (Hb) concentrations, total WBC count, RBC count, differential WBC count and packed cell volume (PCV). Blood parameters were counted by the use of the hematological analyzer system ( coulter differential analyzer ) which includes WBC, RBC, PCV , Hb and differential WBC count .

\section{- Histopathology of heart :}

It included pathological and histological Studies. After anesthesia of mice with chloroform, the heart of the mice were visually inspected and dissected. Portions of heart muscle and cysts in them were prepared for the histopathological study. Tissues were processed according to Drury et al.(1967) and Humanson (1972), briefly the tissue from the heart collected and placed in $10 \%$ formalin for histopathological studies and dehydrated by several dilutions of ethanol alcohol dealcoholization with xylol, then embedded with paraffin wax blocked (3-5) mm thickness sections were obtained by microtome. The sections were put on glass slides deparaffinised with xylol, rehydrated by alcohol and stained by hematoxyline and eosin,.

\section{Results and Discussion}

Echinococcus disease is common in many parts of the world and affects the heart in $0.5-2 \%$ of cases. Major complications result almost always from rupture of the cysts either in the pericardium or in the heart chambers. Death may occur from anaphylactic shock, cardiac tamponade, acute pulmonary embolism, subacute or chronic pulmonary hypertension, systemic embolisation especially in the central nervous system, or secondary generalised hydatidosis. To allow preventive surgical treatment to be undertaken the diagnosis must be made before such complications occur (Tuzun and Hekimoglu, 2001). The examination of experimentally infected males Balb/c mice with protoscolices of hydatid cyst after six months - post infection revealed of presence of hydatid cyst in heart as well with liver, spleen, mesenteries, kidneys and lungs.one mice only from total number of experimentally infected animals was reported Hydatid cyst in heart and in percent about $0.4 \%$. Ian (1985) explain that Hydatid cysts develop in the myocandium, about $60 \%$ in the wall of the left ventricle and $7 \%$ in the interventniculan septum. Symptoms are usually absent or nonspecific and include chest pain, dyspnea on exercise, and fever. Eosinophilia occurs in $20 \%$ of cases and may be associated with recent rupture . A septal cyst can produce conduction defects, and protrusion into a cardiac chamber may intermittently block a valve and cause syncope . Rupture into the pencardial cavity produces tamponade and death, an effusion, pericarditis, or multiple penicardial cysts . Rupture into the cardiac chambers occurs most often in the right ventricle and can cause anaphylaxis or pulmonary or systemic embolism of daughter cysts (Dahniya et al., 2001).
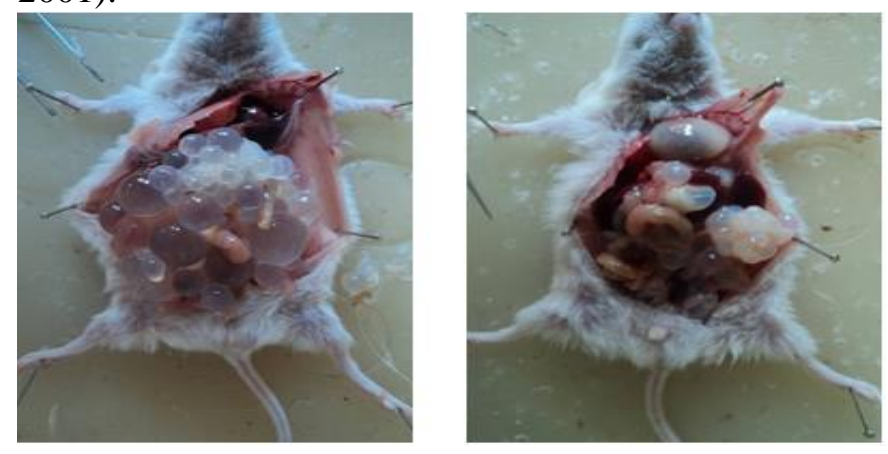

Figure (1) : Pictures of male mice Balb $\backslash \mathrm{C}$ strain after six months post- infection 
Blood parameters were checked in the present study to examine the overall health of experimental animals after infection . RBC, PCV, and $\mathrm{Hb}$ were measured and were found decreased in mice with cardiac hydatidosis reporting 6.1 of RBC , 25.3 of PCV and 7.2 of $\mathrm{Hb}$, therefore, infection of heart with hydatid cyst affect on blood parameters and these results referred to anemia which is regarded as one of heart infection signs with hydatid cyst. so these results were unlike to AlMobarak (2006) and Moraitaki etal.(2010) studies since they are not report infection with hydatid cyst in the heart . The following table explain blood parameter for heart case with hydatidosis:

Table(1): Blood parameters of experimentally infected heart of mice with hydatid cyst

\begin{tabular}{|c|c|c|c|c|c|c|c|c|}
\hline \multirow[b]{3}{*}{ Cases } & \multicolumn{8}{|c|}{ Nean of WBC, RBC, $\mathrm{PCV}, \mathrm{Hb}$ and dWBC of infected mice } \\
\hline & \multirow[b]{2}{*}{ WBC } & \multirow[b]{2}{*}{$\mathrm{RBC}$} & \multirow[b]{2}{*}{$\mathrm{PCV}$} & \multirow[b]{2}{*}{$\mathrm{Hb}$} & \multicolumn{4}{|c|}{ Differential WBC } \\
\hline & & & & & $\mathrm{L}$ & $\mathrm{N}$ & $\bar{E}$ & $\bar{M}$ \\
\hline Healthy control & 14.0 & 9.68 & 34.8 & 13.8 & 56 & 49 & 2 & 1 \\
\hline Heart Infected case & 18.37 & 6.1 & 25.3 & 7.2 & 70 & 48 & 6 & l \\
\hline
\end{tabular}

L:lymphocyte; N: neutrophile ; M: Monocyte ; E: eosinophile

The results were also found that the numbers of WBC have increased like eosinophils and lymphocyte which explain 18.37 of WBC , 70 of lymphocyte and 6 of eosinophils. These results agreed with the study of $\mathrm{Al}-$ Nasiri (2006) and Moraitaki etal.(2010) who found an increase in the number of leukocytes, lymphocytes and eosinophils.Increases in numbers of WBC, lymphocytes and eosinophils were observed in the present study which may be considered as a defense mechanism against the inflammatory processes in the body especially in the liver, spleen and kidneys where the inflammation stimulates the bone marrow to produce a large number of WBC since the infection with hydatid cyst were found in all previous organs as well with heart. The increase of the eosinophil count could be attributed to the long period of the disease. Nguyen and Diamond (2000) explained that eosinophilia was produced due to the ability of parasites to infect the tissue and this agreed with $\mathrm{Al}$ - Humairy (2010) study . The results have showed increases in the focal inflammatory cell of the infected organs with hydatid cyst, the current study explain there is granulomatous tissue in the pericardium region of the heart (as the following picture explain). Mendez - Sanchez etal.(2003) mentioned that the number of lymphocytes and macrophages were increased in the tissues of organs infected with hydatid cysts. Three layers of hydatid cyst can be seen in figure 2,C and include fibrous layer, laminated layer, and germinal layer or endocyst after six months post- infection.
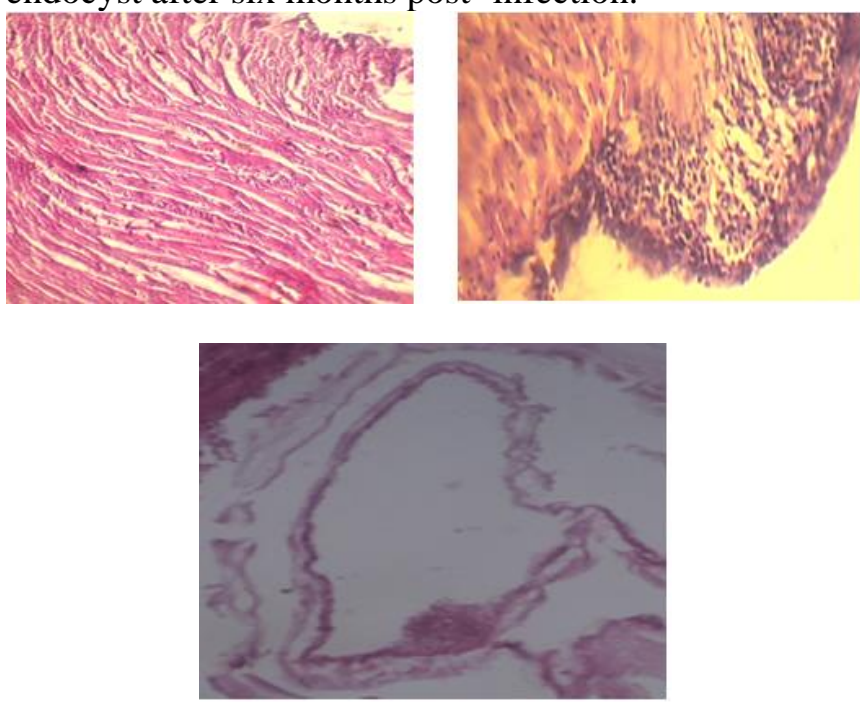

Figure (2): A: normal tissue of cardiac muscle, B: Myocarditis (granulomatous tissue) C: Hydatid cyst with three layers and cyst content

\section{$\underline{\text { References }}$}

- Al - Humairy , A. KH. (2010). Evaluation of the Activity Datura stramonium Seeds Extracts on Growth and Development of Hydatid Cysts for Echinococcus granulosus in White Mice Balb/c (Therapeutic , Histologic and Immunologic Study ).Ph. D. Thesis . College of Science, Kufa University.

- Al - Mobarak, Z.A. (2006). Effect of peel extracts of Punica fruits on on echinococcosis of Echinococcus granulosus . M. Sc. Thesis, College of Education ., Kufa University.

- Al- Nasiri, F.S. (2006). Biological and immunological study of hydatid cyst formation in albino mice . Ph.D. Thesis, College of Education , University of Baghdad .

- Dahniya , Hanna, and Ashebu.(2001). The imaging appearance of $\mathrm{HD}$ at some unusual sites. Br J Radiol . 74:283-289.

- $\quad$ Drury , R.A.V. ; Wallington , E.A. and Cameron , R. (1967). Carleto 's histological technique 4th ed Oxford university press, New York . And Toronto.

- Humanson, G. L. ( 1972 ). Animal tissue techniques . 3rd ed., W. H. Freeman and Company, San Fransisco, USA . 
- Ian begges (1985). The radiology of hydatid disease. AJR 145:639-648.

- Jain, N.C. (1986). Schalm's Veterinary Hematology. 4th ed. Philadelphia: Lea \& Febiger, : 20-86.

- $\quad$ Kilani, El Hammami, and Horchani. (2001) . HD of the liver with thoracic involvement. World $\mathbf{J}$ Surg . 25:40-45.

- Mendez-Sanchez, N. ; Vega, R. ; Cortes, R. ;Corona, R. ; Bahena, R. and Uribe, M. (2003). Hepatic Echinococcus granulosus. A case report. Annals , hepatol. , 2(2) : 99-100.

- $\quad$ Moraitaki, P.; Roussi, P.; Emmanouil, Y. Pechlivanidou, R.; Bitsakou, C.; Konstantinou, M. and Marosis, K. (2010). Pulmonary echinococcosis presenting as a pulmonary mass with fever and haemoptysis; a case report. Pneumon. J. 23, (2): 180 - 183.

- Nguyen, D.T. and Diamond,L.W. (2000) . Diagnostic hematology. 1st ed. Butter Worth Heinemann, Oxford. P.96 - 98.

- $\quad$ Pedrosa, Saiz, Arrazola , Ferreiros and Pedrosa . (2000) . HD: radiologic and pathologic features and complications. RadioGraphics . 20:795-817.

- $\quad$ Schalm, O.W.; Jain, N.C. and Carrol, E.J. (1975). Veterinary hematology. Leo and Febiger, ed. Philadelphia. Pp: 152-140.

- Smyth, J. D. (1964). The biology of hydatid organisms. Adv. Parasitol. , 2: 169-219.

- $\quad$ Tuzun and Hekimoglu . (2001). Various locations of cystic and alveolar HD: CT appearances. J Comput Assist Tomogr . 25:81-87. 